

DOI:10.22144/ctu.jsi.2021.043

\title{
ƯớC LƯỢG MỨC SÃN LÒNG CHI TRẢ ĐỐI VỚI PHÂN SINH KHỐI LỎNG CỦA NÔNG Hộ TRỒNG CÂY ĂN TRÁI TỈNH BẾN TRE
}

\author{
Huỳnh Việt Khải ${ }^{1 *}$, Huỳnh Thị Đan Xuân ${ }^{1}$ và Trần Ngọc Xứng ${ }^{2}$ \\ ${ }^{1}$ Khoa Kinh tế, Trường Đại học Cần Tho \\ ${ }^{2}$ Sinh viên Khoa Kinh tế, Truờng Đại học Cần Tho \\ *Người chịu trách nhiệm về bài viết: Huỳnh Việt Khải (email: hvkhai@ctu.edu.vn)
}

\section{Thông tin chung:}

Ngày nhận bài: $12 / 04 / 2021$

Ngày nhận bài sủa: $27 / 05 / 2021$

Ngày duyệt đăng: 15/11/2021

Title:

Estimating the willingness to pay of fruit farmers for organic liquid biomass fertilizer in Ben Tre province

\section{Tù khóa:}

Mức sã̃n lòng chi trả (WTP), Phân sinh khối, Phuơng pháp đánh giá ngẫu nhiên (CVM)

\section{Keywords:}

Biomass fertilizer, contingent valuation model (CVM), willingness to pay (WTP)

\begin{abstract}
With the goal of moving towards sustainable agriculture by reducing the use of chemical fertilizers, the contingent valuation model (CVM) was used to assess the demand of fruit growers through estimating their willingness to pay for the proposed organic liquid biomass fertilizer in Cho Lach district, Ben Tre province. The results showed that over $60 \%$ of respondents supported and agreed to buy the liquid biomass fertilizer with a willingness to pay or a price around VND 172,000 per ton. Farmers who are older, more highly educated, and have used bio-organic fertilizers in the past, are more interested in and more likely to pay the liquid biomass fertilizer.
\end{abstract}

\section{TÓM TẮT}

Với muc tiêu huớng tới nông nghiệp bền vũng bằng việc giảm liều lương sư dụng phân bón hóa học, phuoong pháp đánh giá ngẫu nhiên (CVM) được sử dụng trong nghiên cứu để đánh giá nhu cầu của người dân trồng cây ăn trái thông qua uớc luợng mức sã̃n lòng chi trả của ho đối với việc sư dụng phân sinh khối lỏng tại huyện Chợ Lách, tỉnh Bến Tre. Kết quả nghiên cứu cho thấy trên $60 \%$ đáp viên ủng hộ và đồng ý mua phân sinh khối lỏng được đề xuất với mức sẵn lòng chi trả hay múc giá khoảng 172.000 đồng/tấn. Nhũng nông dân lớn tuổi, trình độ học vấn cao, và đã tù̀ng sủ dụng phân hũu co sinh hoc trong quá khư có xu hướng thich và sắn sàng chi trả cao hơn cho phân sinh khổi lỏng.

\section{GIỚI THIÊU}

Bến Tre là địa phương có diện tích trồng cây ăn trái lớn thứ ba ở Đồng bằng sông Cửu Long với gần 28 ngàn ha và sản lượng đạt trên 335 ngàn tấn/năm (Cao Đằng, 2019). Diện tích cũng như năng suất của các loại cây ăn trái ở địa phương này ngày càng tăng là nhờ áp dụng những tiến bộ về khoa học kĩ thuật, mở rộng diện tích đất canh tác, đa dạng cây trồng theo hướng hiện đại. Ngoài ra, việc sử dụng phân bón hóa học và thuốc nông dược hóa học đã góp phần đáng kể cho năng suất cây trồng tăng lên. Tuy nhiên, nó cũng làm nảy sinh các vấn đề như ô nhiễm môi trường, ô nhiễm thực phẩm, điều kiện môi trường sống bị giảm sút, nguyên nhân có thể là do sử dụng quá mức phân bón hóa học, thuốc bảo vệ thực vật.

Do việc sử dụng phân bón hóa học và thuốc bảo vệ thực vật kéo dài với lượng lớn, chất lượng đất bị suy thoái làm cho năng suất thấp và giảm chất lượng sản phẩm. Để giảm thiểu những tác động bất lợi của canh tác thông thường, sản xuất nông nghiệp hữu cơ đã trở nên quen thuộc như bổ sung dinh dưỡng của chất hữu cơ và thực vật. Thực tế là người tiêu dùng rất quan tâm đến tầm quan trọng của việc lựa chọn thực phẩm an toàn tốt cho sức khỏe đã được ghi nhận trong các nghiên cứu trước đây. 
Có rất nhiều quốc gia trên thế giới đã thực hiện mô hình canh tác hữu cơ. Ở Châu Âu, các chính sách của chính phủ nhằm kích thích ngành nông nghiệp hữu cơ như việc trợ cấp cho các nhà sản xuất nông nghiệp, người tiêu dùng, giáo dục và hỗ trợ dưới hình thức nghiên cứu. Hiện nay, các nhà nghiên cứu cùng với nông dân đang quan tâm đến các nguồn nông nghiệp tự nhiên như chất thải của con người và chất thải động vật để sản xuất phân bón hữu cơ cho sản xuất nông nghiệp. Việc sử dụng phân và nước tiểu của con người đã trở nên phổ biến như một loại phân bón ở một số quốc gia.

Tuy nhiên, tỉnh Bến Tre vẫn chưa thể tận dụng nguồn lợi thế này từ chất thải của con người do công nghệ hạn chế. Trong khi đó, nông dân địa phương phải trả chi phí rất cao cho phân bón, đặc biệt là phân hoá học. Theo báo cáo kinh tế xã hội tỉnh Bến Tre, có khoảng 1.763 tấn phân hóa học và 4,6 tấn thuốc trừ sâu mỗi năm được sử dụng cho nông nghiệp tại tỉnh Bến Tre (Ủy ban nhân nhân tỉnh Bến Tre, 2017). Ngoài ra, nông dân thường có thu nhập thấp hơn so với người dân thành thị, và hơn nữa, họ phải phân bổ $10 \%$ - 20\% doanh thu bán trái cây để mua phân bón hóa học chưa tính chi phí mua thuốc trừ sâu (Ủy ban nhân dân huyện Chợ Lách tỉnh Bến Tre, 2015). Sản xuất nông nghiệp thân thiện với môi trường, kết hợp với mong muốn của người tiêu dùng đối với thực phẩm an toàn không chứa hoá chất tổng hợp là cần thiết cho một nền nông nghiệp bền vững.

Tháng 3 năm 2015, Ủy ban nhân dân thành phố Đà Nẵng, Cơ quan Hợp tác Quốc tế Nhật Bản (JICA) và thị trưởng thành phố Chikujo đã thảo luận để đưa ra giải pháp tốt nhất cho thành phố Đà Nằng về tái chế chất thải của con người. Sau đó, dự án "Tái chế chất thải hữu cơ thành phân hữu cơ sinh học để sản xuất nông nghiệp sạch và thân thiện với môi trường ở Đà Nẵng" được ký hợp đồng. Đây là dự án đầu tiên ở Việt Nam sản xuất phân bón lỏng từ chất thải của con người được xử lý bằng công nghệ tiên tiến của Nhật Bản (Hong et al., 2017).

Trong tương lai, giả định sẽ có một nhà máy được đặt tại tỉnh Bến Tre để giúp các hộ nông dân có thể tiếp cận và sử dụng phân bón lỏng cho cây trồng của mình để giảm chi phí sản xuất và đặc biệt là giảm ô nhiễm môi trường. Mục đích của việc xây dựng nhà máy này là thúc đẩy việc sử dụng phân bón lỏng hữu cơ trong nông nghiệp và nâng cao nhận thức của người dân về bảo vệ môi trường thông qua hỗ trợ nông dân biến rác thải của con người thành phân bón hữu cơ để làm nông nghiệp với giá thấp. Vì nó là một sản phẩm hoàn toàn mới trên thị trường ở Bến Tre nên việc đánh giá nhu cầu của sản phẩm này trên thị trường là rất quan trọng. Sự bền vững của một sản phẩm kinh doanh nông nghiệp đòi hỏi phải đảm bảo sự sẵn lòng chi trả của khách hàng mục tiêu.

Xuất phát từ những vấn đề cấp bách đó mà nghiên cứu này với mục tiêu chung là tìm hiểu nhận thức, thái độ cũng như sự sẵn lòng chi trả của nông hộ đối với phân sinh khối lỏng. Từ đó, một số kiến nghị để khuyến khích các nông hộ trồng cây ăn trái mua phân sinh khối lỏng để giảm chi phí sản xuất, tăng lợi nhuận cho nông hộ, góp phần bảo vệ môi trường, và bảo vệ hệ sinh thái.

\section{PHƯƠNG PHÁP PHÂN TÍCH VÀ THU THẬP SỐ LIỆU}

Các lý thuyết cơ bản của cách tiếp cận phương pháp đánh giá ngẫu nhiên (CVM) được đề xuất bởi Hanemann \& Kanninen (1998). Phương pháp này yêu cầu trả lời câu hỏi khép kín, cụ thể là liệu đáp viên có chấp nhận trả một số tiền nhất định để có được một sự thay đổi nhất định cho hiện trạng của họ. Giả sử rằng đáp viên được yêu cầu xem xét sự thay đổi từ $Q^{0}$ sang $Q^{l}\left(Q^{l}\right.$ đề cập đến giá trị của hàng hóa không tồn tại như phân sinh khối lỏng, và sự lựa chọn sau được ưa thích hơn sự lựa chọn trước). Được mô tả bởi hàm hữu dụng của đáp viên như sau $V=V(P, Q, M, Z, \varepsilon)$, với $P$ là vector giá cho tất cả các hàng hóa thị trường hiện đang có sẵn, $M$ là thu nhập của đáp viên, $Z$ là vector đặc tính của đáp viên, và $\varepsilon$ là thành phần ngẫu nhiên của hàm hữu dụng. Sau đó, nếu đáp viên được hỏi có sẵn lòng chi trả một lượng tiền $t$ để được giá trị $Q^{l}$ hay không thì câu trả lời của họ sẽ là "có" với điều kiện sau:

$$
\begin{aligned}
& \quad \operatorname{Pr}(c o ́)=\operatorname{Pr}\left\{V\left(P, Q^{l}, M-t, Z\right)+\varepsilon_{1}>V\left(P, Q^{0}, M\right.\right. \\
& \left.-0, Z)+\varepsilon_{0}\right\} \\
& \quad=\operatorname{Pr}\left\{V\left(P, Q^{l}, M-t, Z\right)-V\left(P, Q^{0}, M-0, Z\right)+\varepsilon_{1^{-}}\right. \\
& \left.\varepsilon_{0}>0\right\}
\end{aligned}
$$

Trong đó, $\varepsilon_{o}$ và $\varepsilon_{l}$ là thành phần không quan sát được của hàm hữu dụng, có giá trị kỳ vọng bằng không và có phân phối độc lập và đồng nhất (i.i.d). Nếu chúng ta gọi $\Delta V=V\left(P, Q^{l}, M-t, Z\right)-V\left(P, Q^{0}\right.$, $M-0, Z)$ và $\gamma=\varepsilon_{l}-\varepsilon_{0}$, phương trình (1) trở thành:

$$
\operatorname{Pr}(c o ́)=\operatorname{Pr}(\gamma>-\Delta V)=1-F_{\gamma}(-\Delta V)=F_{\gamma}(\Delta V)
$$

Với $F_{\gamma}(\Delta V)$ là hàm mật độ xác suất tích lũy (cdf) của mức sẵn lòng chi trả lớn nhất của đáp viên.

Phương pháp định giá ngẫu nhiên ước tính giá trị trung bình và trung vị của mức sẵn lòng chi trả dựa vào hệ số tự do của mô hình hồi quy và hệ số của biến Bid; cùng với hệ số của các biến về kiến thức, thái độ và đặc điểm kinh tế - xã hội khác. Mô hình 
Probit và Logit là hai mô hình thường được sử dụng để phân tích các nhân tố ảnh hưởng đến mức sẵn lòng chi trả trong phương pháp định giá ngẫu nhiên. Mô hình Logit được sử dụng trong nghiên cứu này với công thức ước lượng hệ số được trình bày như sau:

$$
\begin{aligned}
\operatorname{Pr}(\text { có }) & =F_{\gamma}(\Delta V)=\frac{1}{1+\exp (-\Delta V)} \\
& =\frac{1}{1+\exp -\left(\alpha+\beta_{1} B I D+\beta_{2} X\right)}
\end{aligned}
$$

Với $\alpha$ và $\beta$ là các hệ số được ước lượng và $B I D$ là mức giá chi trả cho phân sinh khối lỏng được đề xuất trong bản câu hỏi.

Mô hình Logit được ước lượng bằng phương pháp ước lượng hợp lý tối đa (Maximum Likelihood Estimation- MLE). Với $R_{k}$ biểu thị câu trả lời của đáp viên thứ $k$, ta có công thức sau:

$$
\begin{gathered}
\operatorname{Pr}(\text { có })=\operatorname{Pr}\left(R_{k}=1\right)=\operatorname{Pr}\left(\gamma_{k}<\Delta V_{k}\right)=F_{\gamma}\left(\Delta V_{k}\right)(4) \\
\operatorname{Pr}(\text { không })=\operatorname{Pr}\left(R_{k}=0\right)=\operatorname{Pr}\left(\gamma_{k}<\Delta V_{k}\right)=1- \\
F_{\gamma}\left(\Delta V_{k}\right)
\end{gathered}
$$

Vì vậy, hàm số $\log$ - likelihood được thiết lập như sau:

$$
\begin{array}{r}
\log L=\sum_{k=1}^{N}\left\{R_{k} F_{\gamma}\left(\Delta V_{k}\right)+\left(1-R_{k}\right) \ln \left(1-F_{\gamma}\right.\right. \\
\left.\left.\left(\Delta V_{k}\right)\right)\right\}
\end{array}
$$

Giống như một số nghiên cứu trước đó (Khai, 2017; Khai \& Yabe, 2014), giá trị trung bình và trung vị của mức sã̃n lòng chi trả trong trường hợp này là như nhau và được tính theo công thức:

Giá trị trunng bình của $\mathrm{WTP}=$ Giá trị trung vị của WTP $=-\frac{\left(\widehat{\alpha}+\widehat{\beta_{2}} \bar{X}\right)}{\widehat{\beta_{1}}}$

Số liệu sơ cấp được thu thập bằng việc phỏng vấn trực tiếp nông dân trồng cây ăn trái ở huyện Chợ Lách, tỉnh Bến Tre, huyện có diện tích trồng cây ăn trái lớn nhất tỉnh. Kịch bản bắt đầu với sự mô tả về thực trạng sử dụng phân bón hóa học hiện nay và mô tả về phân sinh khối lỏng làm từ phân và nước tiểu người. Giới thiệu sự tiện lợi của phân sinh khối lỏng và đề xuất sản phẩm phân sinh khối lỏng mới được làm từ phân và nước tiểu người ở tỉnh Bến Tre.

Về công nghệ sản xuất thì quy trình sản xuất phân sinh khối lỏng như sau: Sau khi phân và nước tiểu người được lấy từ các khu dân cư, văn phòng và các công trình công cộng (trường học, các siêu thị...) được đưa đến nhà máy xử lý và sản xuất tại tỉnh Bến Tre. Ở đây, nguyên liệu được xử lý bằng công nghệ hệ thống xử lý tự sinh nhiệt, là công nghệ hiện đại của Nhật Bản. Trong quá trình xử lý, các vi khuẩn gây hại cho đất, cây trồng và ảnh hưởng đến sức khỏe của con người đã được loại bỏ.

Hàm lượng $\mathrm{N}, \mathrm{P}, \mathrm{K}, \mathrm{Ca}$ và các khoáng chất trong phân và nước tiểu người rất cao. Đây là những thành phần không thể thiếu được trong việc sinh trưởng và phát triển của cây trồng. Phân và nước tiểu người được tái sản xuất thành phân sinh khối lỏng, để sử dụng trong sản xuất nông nghiệp. Sau đó, câu hỏi về mức sẵn lòng chi trả được đưa ra cho đáp viên trả lời: “Ông/Bà có sẵn lòng trả khoản tiền là ... đồng/tấn cho phân sinh khối lỏng ở tỉnh Bến Tre hay không?".

Dựa vào kết quả của nghiên cứu trước đó của Hong et al. (2017) tại Đà Nẵng, năm mức giá được đưa ra khảo sát là: 100.000 đồng, 120.000 đồng, 140.000 đồng, 160.000 đồng, và 180.000 đồng cho một tấn phân sinh khối lỏng. Các mức giá được lựa chọn dựa trên việc thiết lập đường cầu theo giá, mức giá được đưa ra tăng dần dọc theo đường cầu để xem xét sự biến động về số lượng đáp viên chấp nhận chi trả và mức sằn lòng chi trả cho việc sử dụng phân sinh khối lỏng khi giá tăng lên. Sau khi phỏng vấn thử, các mức giá được cho là khá phù hợp với khả năng chi trả của các hộ nông dân nên năm mức giá này được sử dụng để thực hiện nghiên cứu.

Về cách chọn hộ phỏng vấn, trước tiên tham khảo danh sách các hộ nông dân có trồng cây ăn trái trên địa bàn nghiên cứu từ trạm khuyến nông của huyện Chợ Lách. Sau đó, phỏng vấn viên trực tiếp đến địa bàn nghiên cứu và tiến hành chọn nông hộ để phỏng vấn theo phương pháp chọn mẫu thuận tiện. Nghiên cứu đã phỏng vấn trực tiếp tổng cộng 110 hộ nông dân trồng cây ăn trái (Với năm mức giá, 22 hộ được phỏng vấn cho mỗi mức giá) ở hai xã có diện tích trồng trái cây lớn của huyện là Vĩnh Bình và Long Thới. Mỗi nông dân sẽ được hỏi họ có sẵn lòng chi trả một mức giá đã được xác định trong 5 mức giá trên hay không? Nếu nông dân đồng ý, sẽ tiếp tục hỏi mức độ chắc chắn chi trả này. Ngược lại, nếu nông dân không đồng ý thì hỏi lý do không đồng ý.

Hàm Logit với các biến được mô tả ở Bảng 1 được sử dụng để ước lượng mức sẵn lòng chi trả cho phân sinh khối lỏng có dạng:

$$
\begin{aligned}
& \quad \operatorname{Logit}(P)=\ln \left(\frac{P}{1-P}\right)=\beta_{0}+\beta_{1} \text { Bid }+ \\
& \beta_{2} \text { Tuoi }+\beta_{3} \text { Trinhdo }+\beta_{4} \text { Nhankhau }+ \\
& \beta_{5} \text { Thunhap }+\beta_{6} \text { Dientich }+\beta_{7} \text { Gioitinh }+ \\
& \beta_{8} \text { Huuco }+\beta_{9} \text { Taphuan }+\beta_{9} \text { Kinhnghiem }+ \\
& \beta_{9} \text { Cpphanhoahoc }
\end{aligned}
$$


Bảng 1. Các biến được sử dụng trong mô hình Logit

\begin{tabular}{|c|c|c|}
\hline Tên biến & Mô tả & Đơn vị đo lường \\
\hline$P$ & $\begin{array}{l}\text { Xác suất chấp nhận chi trả cho phân sinh khối } \\
\text { lỏng của đáp viên }\end{array}$ & $\begin{array}{l}\text { Biến phụ thuộc nhận giá trị } 0 \text { nếu không } \\
\text { đồng ý và giá trị } 1 \text { nếu đồng ý }\end{array}$ \\
\hline Bid & Mức giá Bid cho 1 tấn phân sinh khối lỏng & $\begin{array}{l}\text { Nhận các giá trị: } 100,120,140,160 \text {, và } \\
180 \text { nghìn đồng/tấn }\end{array}$ \\
\hline Tuoi & Tuổi của đáp viên tính tới thời điểm nghiên cứu & Số năm \\
\hline Trinhdo & Số năm đi học của đáp viên & Số năm \\
\hline Nhankhau & Số lượng thành viên trong gia đình của đáp viên & Số người \\
\hline Thunhap & Tổng thu nhập thuần từ trồng cây ăn trái của hộ & Triệu đồng/1.000m²/năm \\
\hline Dientich & Tổng diện tích đất sản xuất nông nghiệp của hộ & $\mathrm{m}^{2}$ \\
\hline Gioitinh & Giới tính của đáp viên & Nhận giá trị 1 nếu là nam; 0 nếu là nữ \\
\hline Ниисо & Sử dụng phân hữu cơ & Nhận giá trị 1 nếu là có; 0 nếu là không \\
\hline Taphuan & Tập huấn & Nhận giá trị 1 nếu là có; 0 nếu là không \\
\hline Kinhnghiem & Kinh nghiện & Số năm \\
\hline Cpphoahoc & Chi phí phân hóa học & Nghìn đồng/1.000 m²/năm \\
\hline
\end{tabular}

\section{KẾT QUẢ VÀ THẢO LUẬN}

Bảng 2 trình bày đặc điểm kinh tế xã hội của đáp viên. Kết quả cho thấy độ tuổi trung bình của đáp viên là 51 tuổi, phần lớn đáp viên là người có kinh nghiệm trong sản xuất, trồng trọt cũng như có nhiều kinh nghiệm trong việc chọn lựa phân bón cho cây

\section{Bảng 2. Đặc điểm của mẫu nghiên cứu}

\begin{tabular}{|c|c|c|c|c|}
\hline Các yếu tố & Trung bình & Độ lệch chuẩn & Giá trị nhỏ nhất & Giá trị lớn nhất \\
\hline Tuổi (Số năm) & 51,182 & 12,307 & 28 & 86 \\
\hline Kinh nghiệm (Số năm) & 15,282 & 10,964 & 1 & 40 \\
\hline Giới tính nam & 0,773 & 0,421 & 0 & 1 \\
\hline Trình độ học vấn (Số năm) & 7,436 & 3,040 & 1 & 15 \\
\hline Số thành viên (Số người) & 3,782 & 1,273 & 1 & 8 \\
\hline Diện tích đất $\left(1000 \mathrm{~m}^{2}\right)$ & 5,414 & 4,682 & 1 & 25 \\
\hline Sử dụng phân hữu cơ & 0,445 & 0,499 & 0 & 1 \\
\hline $\begin{array}{l}\text { Thu nhập thuần từ cây ăn trái } \\
\text { (Triệu đông } / 1.000 \mathrm{~m}^{2} / \text { năm) }\end{array}$ & 22,385 & 12,533 & 4 & 60 \\
\hline
\end{tabular}

Tỷ lệ đáp viên nam chiếm 77,3\% do đa phần ở nông thôn nam giới thường là chủ hộ. Vì nam giới là người trực tiếp làm nông nghiệp, trồng cây, bón phân và thường cũng là người đưa ra quyết định sử dụng loại phân nào nên họ hiểu biết rõ về phân đang bón cho cây trồng của mình. Do vậy, tỷ lệ đáp viên là nam giới trả lời phỏng vấn chiếm số lượng nhiều hơn tỷ lệ đáp viên là nữ giới sẽ giúp cho số liệu điều tra chính xác và phù hợp với việc sẵn lòng chi trả cho sản phẩm phân sinh khối lỏng hơn. Trình độ học vấn của đáp viên trung bình khoảng 8 năm đi học và số lượng thành viên trong một hộ bình quân khoảng 4 người, trong đó số thành viên trong gia đình tham gia vào sản xuất nông nghiệp khoảng 2 người với thu nhập thuần bình quân từ cây ăn trái hàng năm của hộ khoảng 22,4 triệu đồng/1.000m2.

Đáp viên có diện tích trồng cây ăn trái trung bình gần 5,5 công $\left(5.500 \mathrm{~m}^{2}\right)$. Hầu hết các đáp viên đều trồng của mình. Theo kết quả khảo sát, các đáp viên có số năm kinh nghiệm trung bình khoảng hơn 15 năm, đáp viên giàu kinh nghiệm nhất là khoảng 40 năm còn đáp viên có ít kinh nghiệm trồng cây ăn trái nhất là 1 năm. Với số năm kinh nghiệm như trên, phần lớn các đáp viên đều có những kiến thức, hiểu biết về phân bón nhất định. là chủ mảnh đất nơi mình đang canh tác, không có thuê thêm đất để trồng trọt. Nhìn chung, diện tích đất canh tác trồng cây ăn trái của các đáp viên đều ở quy mô nhỏ và sản xuất riêng lẻ. Tất cả các đáp viên được phỏng vấn đều có sử dụng phân hóa học và xem đây là loại phân bón chính. Tuy nhiên, có khoảng 44,55\% đáp viên có sử dụng thêm phân hữu cơ bón cho cây ăn trái của mình.

Trong quá trình phỏng vấn nông dân, trước tiên người phỏng vấn thu thập các thông tin liên quan đến sử dụng phân bón hóa học của đáp viên và đồng thời trình bày các vấn đề về an toàn của người tiêu dùng và môi trường hiện nay, đặc biệt là vấn đề suy thoái, bạc màu đất, ô nhiễm môi trường do sử dụng quá mức phân hóa học. Sau đó, phân sinh khối lỏng được giới thiệu, đáp viên được hỏi có đồng ý chi trả cho loại phân này với các mức giá đưa ra hay không và kết quả được thể hiện ở Bảng 3. 
Bảng 3. Số đáp viên sẵn lòng chi trả và không sẵn lòng chi trả cho sản phẩm phân sinh khối lỏng

\begin{tabular}{lcrrrr}
\hline \multirow{2}{*}{$\begin{array}{l}\text { Mức giá } \\
\text { đồng) }\end{array}$} & Số quan sát & \multicolumn{2}{c}{ Sẵn lòng chi trả } & \multicolumn{3}{c}{ Không sã̃n lòng chi trả } \\
\cline { 3 - 6 } & & Tần số & Tỷ trọng (\%) & Tần số & Tỷ trọng (\%) \\
\hline 100.000 & 22 & 16 & 72,7 & 6 & 27,3 \\
120.000 & 22 & 16 & 72,7 & 6 & 27,3 \\
140.000 & 22 & 15 & 68,2 & 7 & 31,8 \\
160.000 & 22 & 11 & 50,0 & 11 & 50,0 \\
180.000 & 22 & 9 & 40,9 & 13 & 59,1 \\
\hline Tồng & 110 & 67 & 60,9 & 43 & 39,1 \\
\hline
\end{tabular}

Bảng 3 cho thấy đa số đáp viên đồng ý chi trả cho sản phẩm phân sinh khối lỏng và mức giá càng cao thì đáp viên đồng ý sẵn lòng chi trả càng giảm. Điều này phù hợp với lý thuyết đường cầu. Cụ thể, ở mức giá thấp nhất 100.000 đồng thì có gần $73 \%$ đáp viên sẵn lòng chi trả cho phân sinh khối lỏng. Trong khi đó, với mức giá cao nhất là 180.000 đồng, chỉ khoảng $41 \%$ đáp viên đồng ý chi trả. Các đáp viên không đồng ý chi trả cho phân sinh khối lỏng với các lý do được trình bày ở Bảng 4 .

\section{Bảng 4. Lý do đáp viên không đồng ý chi trả}

\begin{tabular}{lrr}
\hline Lý do & Tần số & Tỷ trọng (\%) \\
\hline Tôi cảm thấy giá sản phẩm cao & 1 & 2,3 \\
Tôi không quan tâm vấn đề môi trường trong sản xuất & 7 & 16,3 \\
Tôi cảm thấy loại phân này không đạt hiệu quả & 22 & 51,2 \\
Tôi lo lắng phân sẽ ảnh hưởng đến sức khỏe người sử dụng & 1 & 2,3 \\
Tôi không có nhu cầu sử dụng & 23 & 53,5 \\
Tôi không có thông tin nhiều về sản phẩm & 24 & 55,8 \\
Tôi không biết cách sử dụng phân này cho cây trồng của mình & 12 & 27,9 \\
Tôi không thích dùng phân hữu cơ & 4 & 9,3 \\
Lý do khác & 1 & 2,3 \\
\hline
\end{tabular}

Bảng 4 cho thấy đa số các đáp viên không đồng ý chi trả cho phân sinh khối lỏng với lý do rằng họ không có nhiều thông tin về sản phẩm phân sinh khối lỏng (chiếm khoảng 56\%). Tiếp đó là lý do đáp viên không có nhu cầu sử dụng phân sinh khối lỏng với tỷ trọng khoảng $54 \%$, cảm thấy loại phân này không đạt hiệu quả chiếm khoảng $51 \%$, và không biết cách sử dụng loại phân này cho cây trồng của mình chiếm khoảng $28 \%$. Do vậy, khi phân sinh khối lỏng xuất hiện trên thị trường đòi hỏi các thông tin về loại phân này phải được giới thiệu rõ ràng, đầy đủ, và rộng rãi cho tất cả mọi người đều biết và kịp thời nắm bắt, đặc biệt là phải được giải thích và nêu rõ những lợi ích và thuận tiện mà phân sinh khối lỏng này mang lại cho các nông hộ trồng cây ăn trái.

Bảng 5 trình bày các kết quả hồi quy Logit cho các câu hỏi đánh giá ngẫu nhiên CVM. Mô hình 1 được ước tính chỉ với biến độc lập là mức giá lựa chọn (Bid), trong khi mô hình 2 được phân tích bao gồm cả các đặc điểm kinh tế xã hội của chủ hộ và các yếu tố khác ảnh hưởng đến khả năng chi trả cho sản phẩm phân sinh khối lỏng như độ tuổi, trình độ học vấn, kinh nghiệm, tham gia tập huấn, số thành viên trong gia đình, tổng thu nhập thuần từ cây ăn trái, việc sử dụng phân hữu cơ trong quá khứ, chi phí sử dụng phân hóa học. Trước khi ước lượng mô hình, bài viết này đã tiến hành kiểm định sự tồn tại đa cộng tuyến và kết quả cho thấy không tồn tại hiện tượng đa cộng tuyến giữa các biến độc lập trong các mô hình, do không có mối tương quan trong các biến độc lập cao hơn 0,7 (Khai et al., 2020; Khai \& Yabe, 2014).

Hệ số Pseudo $\mathrm{R}^{2}$ ở mô hình 1 và mô hình 2 lần lượt là 0,0381 và 0,2158 cho thấy các biến độc lập trong mô hình 1 và 2 giải thích tương ứng $3,81 \%$ và $21,58 \%$ cho quyết định sẵn lòng chi trả cho phân sinh khối lỏng. Pseudo $\mathrm{R}^{2}$ ở mô hình 2 lớn hơn ở mô hình 1 nên mô hình này tốt hơn. Theo Phan Đình Khôi \&Tăng Thị Ngân (2014), hệ số Pseudo R ${ }^{2}$ trong mô hình này không hoàn toàn giải thích cho sự phù hợp của mô hình, do đó cần xem xét thêm mức độ giải thích chính xác của mô hình bằng phần trăm dự báo đúng của mô hình. Kết quả phân tích cho thấy phần trăm dự báo đúng của mô hình 1 là 60,91\%, mô hình 2 là 73,64\%. Do vậy, mô hình 2 tốt hơn mô hình 1 cho các ước lượng về các yếu tố ảnh hưởng đến sự sẵn lòng chi trả cho phân sinh khối lỏng do cả Pseudo $\mathrm{R}^{2}$ và phần trăm dự báo đúng của mô hình 2 cao hơn mô hình 1 . 
Bảng 5. Kết quả mô hình hồi quy Logit về mức sẵn lòng chi trả cho sản phẩm phân sinh khối lỏng

\begin{tabular}{lrrrr}
\hline \multirow{2}{*}{ Tên biến } & \multicolumn{2}{c}{ Mô hình 1 } & \multicolumn{2}{c}{ Mô hình 2 } \\
\cline { 2 - 5 } & Hệ số & Sai số chuẩn & \multicolumn{1}{c}{ Hệ số } & Sai số chuẩn \\
\hline Bid & $-0,0167^{* *}$ & 0,0072 & $-0,0199^{* *}$ & 0,0084 \\
Tuoi & & & $0,0381^{*}$ & 0,0230 \\
Trinhdo & & & $0,2211^{* *}$ & 0,0928 \\
Nhankhau & & & 0,1049 & 0,2043 \\
Thunhap & & 0,0129 & 0,0225 \\
Dientich & & $-0,0001$ & 0,0001 \\
Gioitinh & & 0,1371 & 0,5595 \\
Huuco & & $1,4122^{* * *}$ & 0,5239 \\
Taphuan & & $-0,0658$ & 0,5273 \\
Kinhnghiem & & 0,0311 & 0,0249 \\
Cpphoahoc & & $-0,0003$ & 0,0002 \\
Hệ số chặn & & $-0,7033$ & 1,9357 \\
Giá trị Log likelihood & $2,8128^{* * *}$ & $-57,7192$ & \\
Pseudo R ${ }^{2}$ & $-70,8046$ & 0,2158 & \\
Phần trăm dự báo đúng & 0,0381 & 7,055 & $73,64 \%$ & \\
Giá trị trung bình WTP & $60,91 \%$ & 172,21 nghìn đồng/tấn \\
( 95\% CI) & 167,93 nghìn đồng/tấn & $(146,46-294,88$ nghìn đồng) \\
\hline
\end{tabular}

Ghi chú: 95\% CI: Khoảng tin cậy 95\% được ước tính bằng phuong pháp Krinsky \& Robb (1986);

***, ** và * turong úng với các múc ý nghĩa 1\%, 5\% và 10\%.

Hệ số của các biến trong mô hình 2 có ý nghĩa thống kê bao gồm mức chi trả (Bid), tuổi (Tuoi), trình độ (Trinhdo), và sử dụng hữu cơ trong quá khứ (Huиco). Hệ số của biến Bid mang dấu âm với mức thống kê $5 \%$ cho thấy nếu giá của phân sinh khối lỏng được đề xuất càng cao thì tỷ lệ đáp viên trả lời đồng ý càng giảm nên phù hợp với lý thuyết của đường cầu. Hệ số của biến Tuoi mang dấu dương với mức ý nghĩa thống kê $10 \%$, nghĩa là nếu nông dân có tuổi càng cao thì khả năng đồng ý chi trả cho phân sinh khối lỏng càng tăng. Điều này có thể được giải thích là do nông dân lớn tuổi hiểu biết nhiều trong việc sử dụng phân bón và tác động xấu của phân hóa học gây ra cho đất, cho môi trường, và cho người tiêu dùng nên khả năng chấp nhận của họ đối với các dạng phân sinh học như phân sinh khối lỏng được dự án đề xuất cũng cao hơn.

Biến Trinhdo tương quan cùng chiều với khả năng chi trả cho phân sinh khối lỏng với mức ý nghĩa $5 \%$ cho thấy nếu nông dân có trình độ học vấn càng cao thì khả năng chi trả của họ cho phân sinh khối lỏng cũng tăng. Điều này có thể giải thích là do họ có kiến thức và thấy được tầm quan trọng của phân sinh khối lỏng, và nhận thức nhiều hơn về việc bảo vệ môi trường. Tương tự, hệ số của biến Huисo cũng mang dấu dương với mức ý nghĩa $1 \%$ cho thấy những nông dân đã từng sử dụng phân hữu cơ trước đó thì có khuynh hướng ủng hộ và sẵn sàng mua phân sinh khối lỏng nếu có mặt trên thị trường. Do nông dân đã từng sử dụng phân hữu cơ nên họ sẽ hiểu rõ hơn những ưu điểm và hiệu quả về lâu dài mà phân sinh khối lỏng mang lại cho cây ăn trái, cho đất trồng và cho môi trường. Đồng thời, các hộ nông dân này sẽ không quá bỡ ngỡ và nhanh chóng quen với việc bón phân sinh khối lỏng như các loại phân hữu cơ khác mà họ đã từng bón.

Công thức (6) được sử dụng để ước lượng mức sẵn lòng trả trung bình của nông hộ cho phân sinh khối lỏng và kết quả ước lượng cũng được trình bày ở Bảng 5 . Mô hình 1 cho thấy mức sã̃n lòng chi trả trung bình cho phân sinh khối lỏng khoảng 168.000 đồng/tấn với khoảng tin cậy $95 \%$ từ 142.000 đồng đến 273.000 đồng/tấn. Nếu bao gồm sự tác động của các yếu tố kinh tế - xã hội của nông hộ thì mức sẵn lòng chi trả cho phân sinh khối lỏng khoảng 172.000 đồng/tấn và dao động từ 146.000 đồng/tấn đến 295.000 đồng/tấn với độ tin cậy 95\%.

\section{KẾT LUẬN VÀ KIẾN NGHI}

Bài viết sử dụng phương pháp CVM để ước lượng mức sẵn lòng chi trả của nông dân trồng cây ăn trái cho việc sử dụng phân sinh khối lỏng được giả định sản xuất tại tỉnh Bến Tre. Kết quả nghiên cứu cho thấy trên $60 \%$ nông dân ủng hộ và đồng ý mua phân sinh khối lỏng này. Nghiên cứu đã phát họa bức tranh về đường cầu của thị trường phân sinh khối lỏng thông qua ước lượng mức chi trả cho loại phân này khoảng 172.000 đồng/tấn, chứng tỏ có tồn 
tại nhu cầu sử dụng phân sinh khối lỏng của nông dân tại thị trường Bến Tre. Ngoài ra, kết quả phân tích hàm Logit cho thấy tuổi, trình độ học vấn, và việc sử dụng hữu cơ trong quá khứ của nông dân ảnh hưởng dương đến khả năng chi trả cho loại phân này.

Việc thiếu vắng thông tin cơ bản về phân sinh khối lỏng và các lợi ích của việc sử dụng phân sinh khối lỏng về môi trường, xã hội, và sức khỏe của người nông dân là trở ngại lớn trong việc quyết định của họ sử dụng loại phân này. Vì vậy, vai trò của các kênh thông tin truyền thông là hết sức quan trọng trong việc tuyên truyền và phổ biến các lợi ích về bảo vệ môi trường và sức khỏe của việc sử dụng phân sinh khối lỏng. Khi người nông dân đã có niềm tin lớn vào phân sinh khối lỏng thì nhu cầu và thị trường của phân sinh khối lỏng trong tương lai ngày càng khả quan hơn.

Tuy nhiên, vì kết quả nghiên cứu này chỉ dừng lại những thông tin về đánh giá nhu cầu của nông dân trồng cây ăn trái ở tỉnh Bển Tre nên cần có một nghiên cứu sâu và chi tiết với việc phỏng vấn nhiều hơn các đối tượng nông dân khác nhau để thể hiện rõ nét đường cầu của phân sinh khối lỏng này. Bên cạnh đó, các nghiên cứu sâu liên quan đến hiệu quả kinh tế của nhà sản xuất phân sinh khối lỏng và các giải pháp đảm bảo thị trường đầu ra ổn định cho các hộ nông dân sử dụng phân sinh khối lỏng trong canh tác là cần thiết.

\section{LỜI CẢM TẠ}

Đề tài này được tài trợ bởi Dự án Nâng cấp Trường Đại học Cần Thơ VN14-P6 bằng nguồn vốn vay ODA từ chính phủ Nhật Bản.

\section{TÀI LIỆU THAM KHẢO}

Cao Đằng (2019). Bến Tre có diện tích cây ăn trái díng thú ba của khu vucc $Đ B S C L$, ngày truy cập 30/10/2020. Địa chỉ: http://thbt.vn/tintuc/tin-trong-tinh/

Hanemann, W. M., \& Kanninen, B. (1998). The Statistical analysis of discrete-response data.
Working paper No.798, Department of Agricultural and Resource Economics and Policy, University of California, Berkeley.

Hong, B., Takahashi, Y., \& Yabe, M. (2017). Determinants of Marketability for Organic Biomass Liquid Fertilizer from Human Waste in Da Nang City, Vietnam. Journal of Environmental Protection, 8(11), 1354-1371.

Khai, H. V., \& Yabe, M. (2014). The demand of urban residents for the biodiversity conservation in U Minh Thuong National Park, Vietnam. Agricultural and Food Economics, 2(1), 1-13..

Khai, H. V., Duyen, T. T. T., \& Xuan, H. T. D. (2020). Willingness to Pay for Certified Safer Pork and Implications for Sustainable Consumption: A Case Study of the Vietnamese Mekong Delta. In Global Food Politics and Approaches to Sustainable Consumption: Emerging Research and Opportunities (pp. 142-156). IGI Global.

Khai, H.V. (2017). An Evaluation of Consumer Willingness to Pay for Organic Vegetables in the Vietnamese Mekong Delta. In Advances in Environmental Research, 59, (pp.183-198). Nova Science Publishers.

Krinsky, I., \& Robb, A. (1986). On Approximating the Statistical Properties of Elasticities. Rev Econ Stat, 68(4), 715 - 719.

Phan Đình Khôi \& Tăng Thị Ngân (2014). Mức sẵn lòng đóng góp của người dân ĐBSCL cho chương trình bảo tồn đa dạng sinh học tại vườn chim Bạc Liêu. Tạp chí Khoa học và Phát triển, 208, 17-26.

Ủy ban nhân dân huyện Chợ Lách tỉnh Bến Tre. (2015). Quy hoạch tổng thể phát triển kinh tế - xã họi huyện Chợ Lách tỉnh Bến Tre đến năm 2020, ngày truy cập 10/04/2018. Địa chỉ: http://www.cholach.bentre.gov.vn

Ủy ban nhân dân tỉnh Bến Tre. (2017). Báo cáo kinh tế xã hội tỉnh Bến Tre năm 2017, ngày truy cập 10/04/2018. Địa chỉ: http://www.bentre.gov.vn 